\title{
Pain Crisis
}

National Cancer Institute

\section{Source}

National Cancer Institute. Pain Crisis. NCI Thesaurus. Code C136820.

An event in which the patient reports pain that is severe, uncontrolled, and causing distress for the patient, family members, or both. 